\title{
Effect of Composite Material Fixing on Hole Accuracy and Defects During Drilling
}

\author{
Krzysztof Ciecieląg ${ }^{1 *}$ \\ 1 Lublin University of Technology, Faculty of Mechanical Engineering, Department of Production Engineering, \\ Nadbystrzycka 36, 20 - 618 Lublin, Poland \\ * Corresponding author's e-mail: k.ciecielag@pollub.pl
}

\begin{abstract}
This study investigates the effect of composite material stiffness on the accuracy of drilled holes and delamination in the drilling process. Two types of composite materials were tested: glass fiber reinforced plastic (GFRP) and carbon fiber reinforced plastic (CFRP). The drilling process was performed using dedicated drill bits. Samples were clamped in a vice of the Avia-VMC $800 \mathrm{HS}$ vertical machining center. Drilling parameters were maintained constant but unsupported element length was changed. The unsupported element length was defined as an unsupported distance between the drilled hole axis and the sample attachment location. The maximum feed force $\mathrm{F}_{\mathrm{f}}$ was determined in the experiments. The accuracy of drilled holes was estimated by optical microscopy. Diameters of the drilled holes were measured. Results made it possible to determine the recommended unsupported element length at which the hole dimensions were within the dimensional tolerance. The study showed a clear decrease in the drilled hole quality and a significant increase in the feed force, especially in the area of tool exit from the workpiece. In addition, the number of delaminated fibers increased with unsupported element length was determined in the study.
\end{abstract}

Keywords: drilling, feed force, glass fiber reinforced plastics, carbon fiber reinforced plastics, delamination.

\section{INTRODUCTION}

Composite materials are artificial materials that are produced from at least two constituent materials [1]. One of the main components of the composite material is resin and the other is reinforcement [2]. In polymer composites, the reinforcement is usually glass, carbon or aramid fiber. Among the polymers used for the matrix, thermosets are the most common. Other types of polymers include thermoplastics and less frequently used elastomers [3]. Properties of composite materials can be improved with modified and auxiliary additives. These additives are added to improve aesthetic and physical properties of composite materials or to ensure their electric charge conduction. Composite materials are usually made of prepregs or mats placed in molds for heating in the autoclave. After being removed from the autoclave, these materials are subjected to machining processes $[1,4]$. Composites are heterogeneous and anisotropic materials that have hard fibers and are therefore included in the group of difficult-to-machine materials [5]. Among many machining processes used in the production of polymer composites, there are: laser processing [6, 7], water jet cutting [8], electroerosion treatment [9], turning [10,11], milling

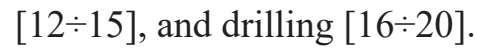

The assembly process often requires combining elements made of composites with other construction materials. Such connections require making additional cuts and deepening. Riveted and bolted joints require undamaged and precise holes. Accurate and defect-free holes affect the strength and precision of the connections. Given a growing demand for the use of composites as construction materials, the methods for shaping composites through machining, including drilling processes, are constantly modified. There are numerous studies on drilling processes such as conventional drilling [16], grinding drilling [18], 
vibration assisted drilling [21], and high speed drilling [22]. The most popular and widely used method is conventional drilling with twist drills. Research studies devoted to this type of machining mainly focus on investigating the influence of variable drilling parameters, tool geometry and material type on the cutting forces and workpiece delamination. The selection of drilling parameters for polymer composites depends on the structure of material, fiber type and orientation as well as the percentage of fibers and matrix [15].

Studies $[17,23,24]$ report technological parameters of drilling, with the rotational speed of the drill being in the range $n=800-8000 \mathrm{rev} / \mathrm{min}$ and the feed per revolution $f=0.05-0.30 \mathrm{~mm} / \mathrm{rev}$. An increase in the feed rate causes an increase in cutting forces during drilling, while an increase in the cutting speed reduces these forces. However, the feed rate has a greater influence on the cutting force than the rotational speed [25]. When selecting the parameters, however, it should be taken into account that with drilling at high speed and low feeds, the temperature of the tool increases and, consequently, its wear increases too. The selection of processing parameters for the drilling process is very important in terms of hole accuracy and composite material damage prevention. Increased tool wear may cause an increase in the number of surface defects, in particular delamination [26, 27].

Fiber orientation affects the average values of the surface roughness parameters $\mathrm{Ra}, \mathrm{Rq}, \mathrm{Rz}$ and Rt. Research [25] has also showed that the highest surface roughness is located in the hole at the entry of the drill into the material, compared to the roughness measured in the hole depth center [25]. There also exist other treatment and measure methods ensuring improved surface roughness [28, 29] thermal characteristic [30] and reduced delamination $[31,32]$; however, they have not been used for the treatment of polymer composites yet.

Composite materials are prone to defect formation during different machining processes [33 $\div 36]$, including drilling. Tool geometry is also an important aspect here. It has been found that a stable drilling process can be achieved by appropriate selection of tool geometry and cutting parameters [27]. In polymer composites, the fibers are subjected to tensile stress, therefore the tools must be very sharp. The fiber must be broken, so that it is not pulled out of the material structure. For drilling polymer composites, diamond coated (PCD) tools are most widely used; compared to cemented carbide tools, they are better in terms of economy and quality. Despite their higher price, PCD tools are an alternative to carbide tools due to longer tool life and the possibility of using higher cutting speeds [37]. Holes made with diamond coated drill bits exhibit low surface roughness.

Apart from low volumetric efficiency, drilling is characterized by composite material damage in the form of delamination [16]. Aviation industry parts with delamination occurring toward the end of the hole drilling process are rejected [17]. Drilling is often the final operation in the manufacture of components, so a shortage of parts is very costly. The occurrence of this undesired defect is caused by the feed force as the tool leaves the material. Research has shown that minimizing the action of the axial force is possible thanks to the use of a tip angle drill. This cause an increased share of the feed force in relation to the axial force in the drilling process [38]. Initially, there is a sharp increase in the force and torque due to the insertion of the drill into the material $[39,40]$. The maximum force and torque occur when shear breaks the bottom layer of the workpiece [27]. Sharp geometry can reduce not only the degree of delamination but also other types of surface defects such as torn fibers.

To avoid delamination, grinding drilling operations are performed with the use of a core drill [18]. Compared to conventional drilling, the core drill is hollow and there is no pressure force on the fibers, which is considered to be the main cause of delamination [19, 20, 41]. Another type of drilling is vibration-assisted drilling [21]. In vibration-assisted drilling, the process is pulsed and intermittent. Compared to conventional drilling, this type of drilling makes it possible to obtain approximately $25 \%$ less pressure, which results in reduced delamination $[42 \div 44]$. This method also ensures higher drilling efficiency [21] and drill service life $[43,44]$. Due to low efficiency of the conventional drilling process, high speed drilling was introduced

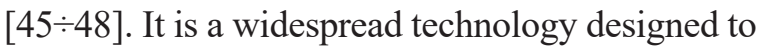
increase productivity. In addition to increasing efficiency, high cutting speeds also reduce the feed force and minimize delamination $[46,48]$.

This study investigates the effect of unsupported element length on the feed force. The relationship between unsupported element length and the formation of delamination and the accuracy of a hole made was also established. A literature review has revealed that this problem requires further research. The study on this problem is also justified by the great prevalence of drilling operations in the industry. GFRP and CFRP are 
the most widely used polymer composite materials. The novelty of this study is that it investigates the impact of hole distance from the support point on the forces and hole accuracy for two different composite materials. In the tests, the maximum feed force was determined in the main zone and in the zone of tool exit from the workpiece. The influence of unsupported element length on the size of delamination was also determined. Hole accuracy was estimated by measuring the elliptical shape of the drilled hole. Based on obtained results, a set of recommendations with respect to drilling operations for different lengths of unsupported element were produced for the industry.

\section{MATERIALS AND METHODS}

Polymer composites supersaturated with epoxy resin $(60 \%$ of the resin volume) reinforced with glass (EGL / EP 3200-120) and carbon (GR / EP 985-GF3070) fibers were used for the tests. Specimens had the form of 300x100 mm panels and were $12 \mathrm{~mm}$ in thickness. Each sample consisted of 50 sheets of prepreg arranged in a $0-90^{\circ}$ system. This system provides strength in all directions in the horizontal plane. The composite materials were prepared while maintaining the appropriate temperature $\left(18-30^{\circ} \mathrm{C}\right)$, humidity $(60 \%)$ and air purity (the amount of solid particles did not exceed 10,000 per $1 \mathrm{~m}^{3}$ ). After that, the samples were placed in packages to create a vacuum. In the next step, the samples were put in the autoclave for 2 hours at a temperature of $177{ }^{\circ} \mathrm{C}$ and at a pressure of $0.3 \mathrm{MPa}$. After the samples were removed from the autoclave, they were left to cool down for 24 hours and then they were subjected to circumferential milling in order to remove residual fibers and resin. A scheme of the sample preparation process is shown in Figure 1.

Drilling operations on the polymer composites were conducted on the Avia-VMC 800 HS vertical machining center. The drilling process was performed using a Dormer drill described by a diameter of $d=10 \mathrm{~mm}$. The drilling process was conducted with its technological parameters maintained constant, i.e., feed speed $v_{\mathrm{f}}=287 \mathrm{~m} /$ min and cutting speed $\mathrm{v}_{\mathrm{c}}=90 \mathrm{~m} / \mathrm{min}$. The length of the hole made was equal to the thickness of the plate, i.e., $12 \mathrm{~mm}$. Force in the drilling of CFRP and GFRP was measured. Different unsupported element lengths $l$ were tested $(l=16,28,40,52$, $64,76,88,100,112,124$ and $136 \mathrm{~mm})$. Figure 2a shows the scheme of specimen support with the length $l$ marked as the unsupported element length. It is the distance between the support of the composite material and the axis of the hole made.

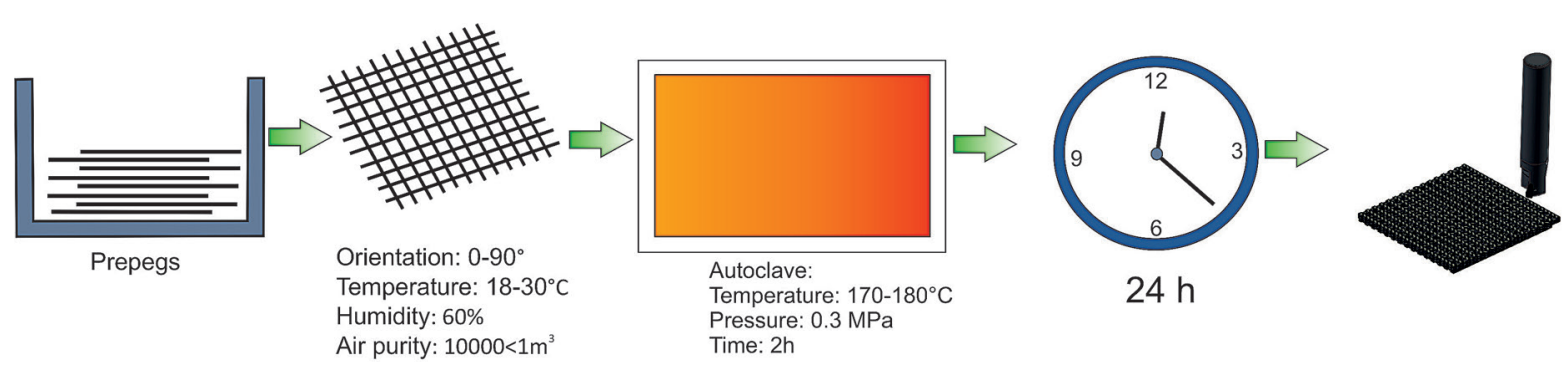

Fig. 1. Scheme of the sample preparation process

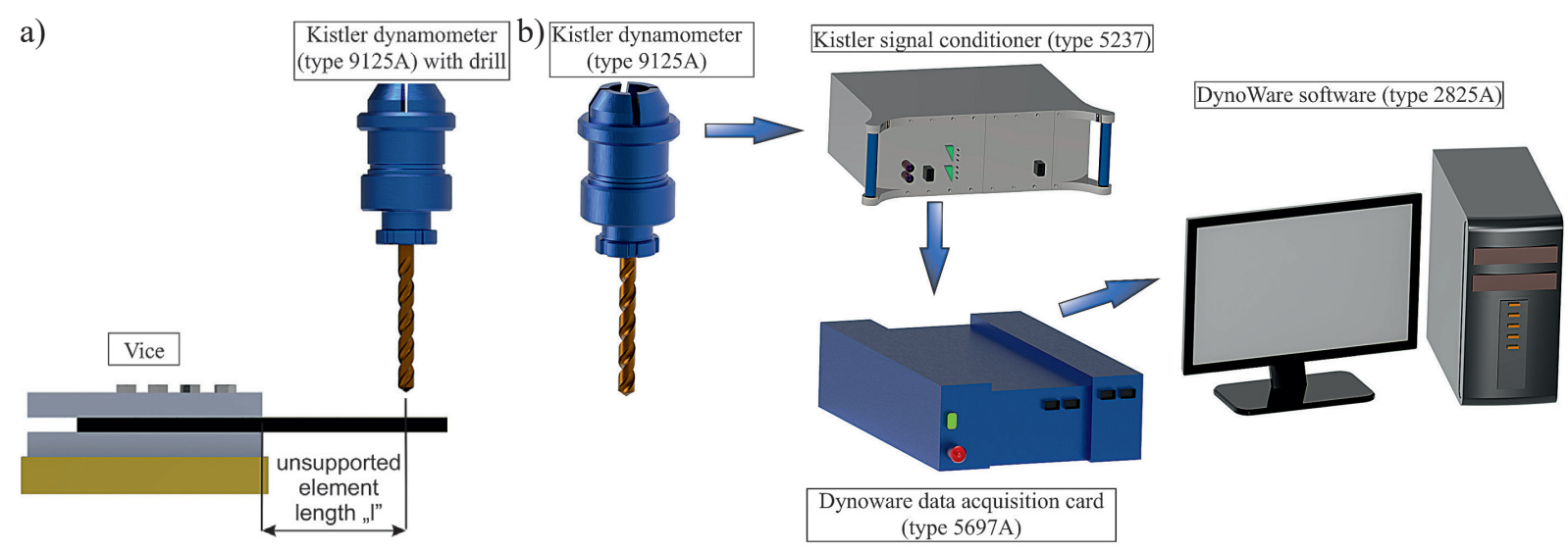

Fig. 2. Scheme of the drilling stand (a) and measuring track elements (b) 
A scheme of the stand for measuring force during drilling is shown in Figure 2b. The tested material was clamped in a vice placed on the machine table. The Kistler dynamometer (type 9125A) was mounted in the spindle to measure feed force. The force acting along the axis of the drill was measured using the Kistler signal conditioner (type 5237) and the Dynoware data acquisition card (type 5697A). Measurement data were recorded with the DynoWare software (type 2825A). Based on obtained results, the maximum feed force during the drilling of holes was calculated. Additionally, the maximum feed force in the area of tool exit from the workpiece was determined.

After drilling, the influence of the unsupported element length 1 on the delamination and accuracy of the hole made was measured. Delamination was determined by measuring the length of torn fibers at the exit of the drill bit. Measurements were made with the Keyence VHX-5000 optical microscope at X100 magnification. Graphs showing the average fiber lengths (delamination) for both tested materials were plotted. Figures $3 \mathrm{a}$ and $3 \mathrm{~b}$ show the examples of delamination measurement for the two tested types of polymer composites.

The accuracy of the drilled holes was assessed by measuring their elliptical shape.
Table 1 shows the tolerances for accuracy classes in relation to nominal dimensions (ISO 2768 specifies the accuracy classes and limit deviations for linear dimensions).

The standard specifies four accuracy classes (good, average, coarse, very coarse), of which good and average are mainly taken into account in the construction documentation.

\section{RESULTS AND DISCUSSION}

An analysis of the drilling process for the tested polymer composites started with measuring the feed force acting in the drill axis direction. The measured of the feed force value allowed the assessment of the influence of the unsupported element length on its maximum value. Examples of force curves obtained when drilling a hole in the tested materials are shown in Figures 4a (for GFRP) and 4b (for CFRP). Waveforms of forces for the holes drilled at the greatest distance $(l=136 \mathrm{~mm})$ from the element support point are presented. The " $\mathrm{X}$ " axis shows the successive measurement points (measurement was made every $0.0004 \mathrm{~s}$ ) and the "Y" axis shows the feed force values.

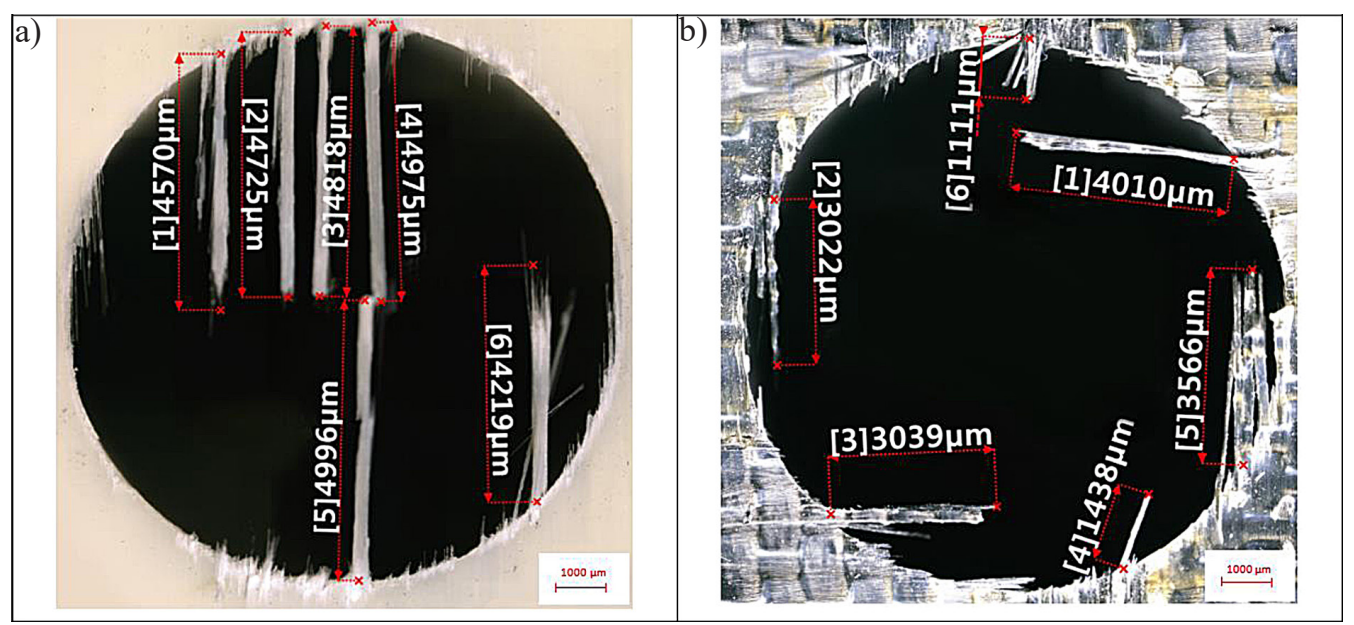

Fig. 3. Examples of delamination measurement in GFRP (a) and CFRP (b)

Table 1. Limit deviations of intolerant linear dimensions (ISO 2768)

\begin{tabular}{|c|c|c|c|c|}
\hline \multirow{2}{*}{$\begin{array}{c}\text { Nominal tolerance } \\
\text { range }[\mathrm{mm}]\end{array}$} & $\mathrm{f}$ (good) $[\mathrm{mm}]$ & $\mathrm{m}$ (average) $[\mathrm{mm}]$ & $\mathrm{c}$ (coarse) [mm] & $\mathrm{v}$ (very coarse) [mm] \\
\cline { 2 - 5 } & \pm 0.05 & \pm 0.10 & \pm 0.15 & - \\
\hline $0.5-3$ & \pm 0.05 & \pm 0.10 & \pm 0.20 & \pm 0.50 \\
\hline$>3-6$ & \pm 0.10 & \pm 0.20 & \pm 0.50 & \pm 1.00 \\
\hline$>6-30$ & \pm 0.15 & \pm 0.30 & \pm 0.80 & \pm 1.50 \\
\hline$>30-120$ & &
\end{tabular}



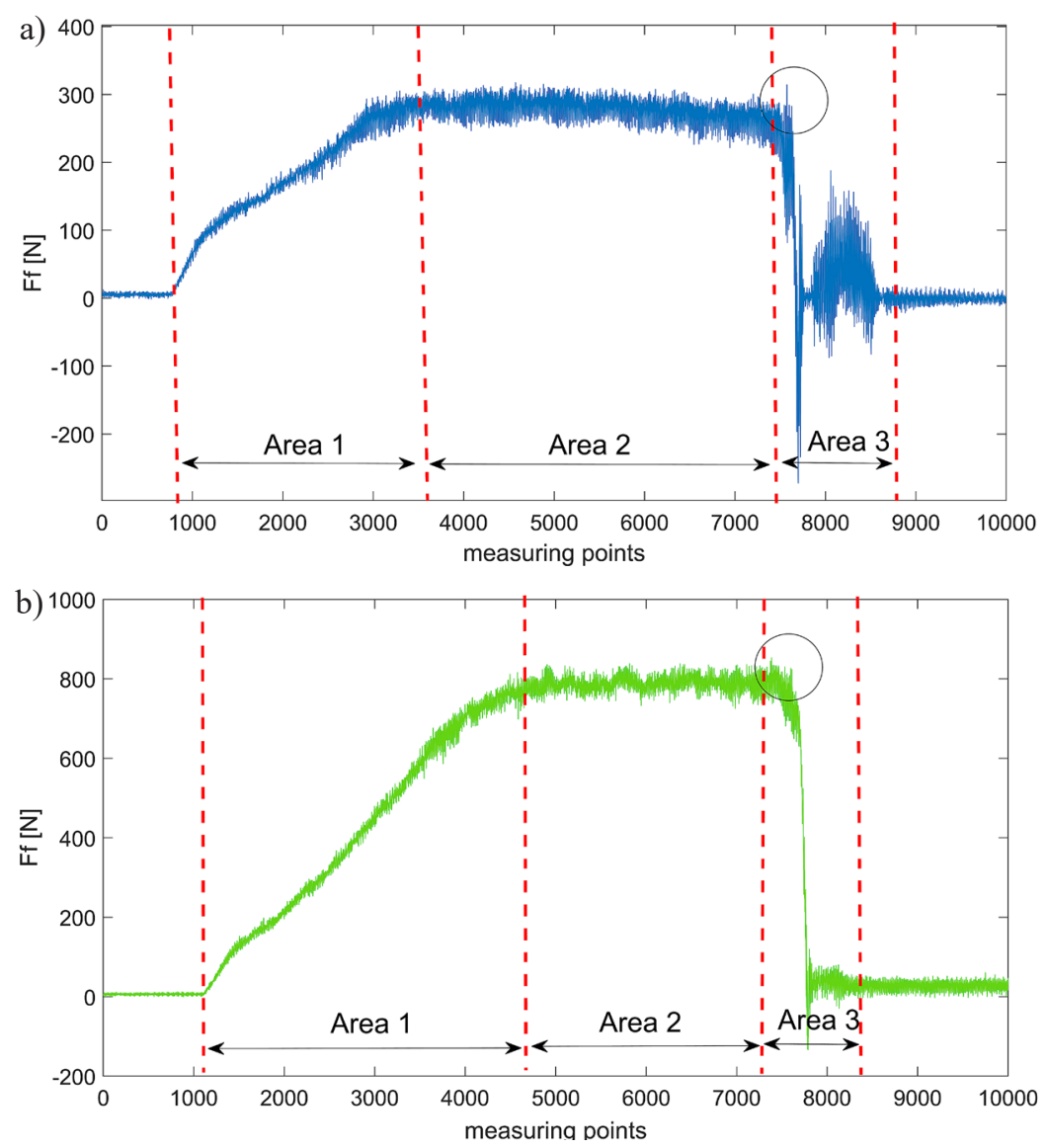

Fig. 4. Feed force waveforms generated in GFRP (a) and CFRP (b) when drilling a hole for the unsupported element length $l=136 \mathrm{~mm}$

Based on the recorded waveforms, several drilling zones can be distinguished, differing from one other by characteristic changes in feed force. In Figures $4 \mathrm{a}$ and $4 \mathrm{~b}$ the analyzed zones are marked with red dotted lines. Force waveforms presented in the graphs show three zones: the zone of tool entrance into the workpiece, the main zone, and the zone of tool exit from the workpiece. In the first zone, there occurs a characteristic, almost linear, increase in the feed force. The linear increase in the feed force in this zone can be explained by an increased length of the cutting edge in contact with the workpiece. In the central zone, referred to as the main drilling zone, the feed force value stabilizes as a result of full engagement of the cutting edges in the drilling process. The third analyzed machining zone is the area where the drill exits the workpiece. This zone is characterized by an initial increase in the feed force (marked with a circle) and then a sharp decrease in this force. The force increase in this zone can be explained by more difficult cutting conditions resulting from the drill coming out of the material. In Figure
$4 \mathrm{a}$, which shows the feed force plot obtained for GFRP, this force is on average $320 \mathrm{~N}$, while for the CFRP composite (Fig. 4b) the force in this area is on average $810 \mathrm{~N}$. The clearly higher maximum feed force for CFRP can be attributed to higher bond strength between carbon fibers. The workpiece length has a significant effect on the feed force in both the main drilling zone and the tool exit zone from the workpiece. Figure 5 shows the relationship between workpiece length and maximum feed force in the main cutting zone and the exit zone. The blue and blue lines mark the results obtained for the GFRP composite, and the green and red lines for the CFRP composite along with standard deviations.

A relationship between the maximum feed force and the unsupported element length is presented in Figure 5. The graph shows that the feed force increases with increasing the length of the element. In the case of the GFRP composite, for the shortest length $l=16 \mathrm{~mm}$, the feed force is $242 \mathrm{~N}$ and increases to $320 \mathrm{~N}$ (for the length $l=136 \mathrm{~mm}$ ). An analysis of the changes in the feed force for the CFRP composite also 


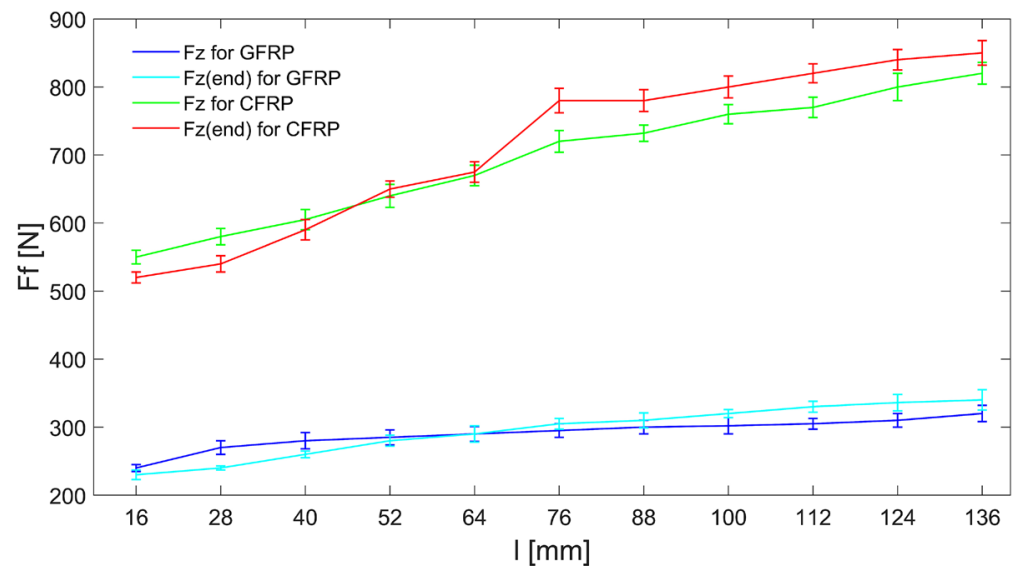

Fig. 5. Graph illustrating the relationship between unsupported element length and feed force in the main cutting zone and in the exit zone

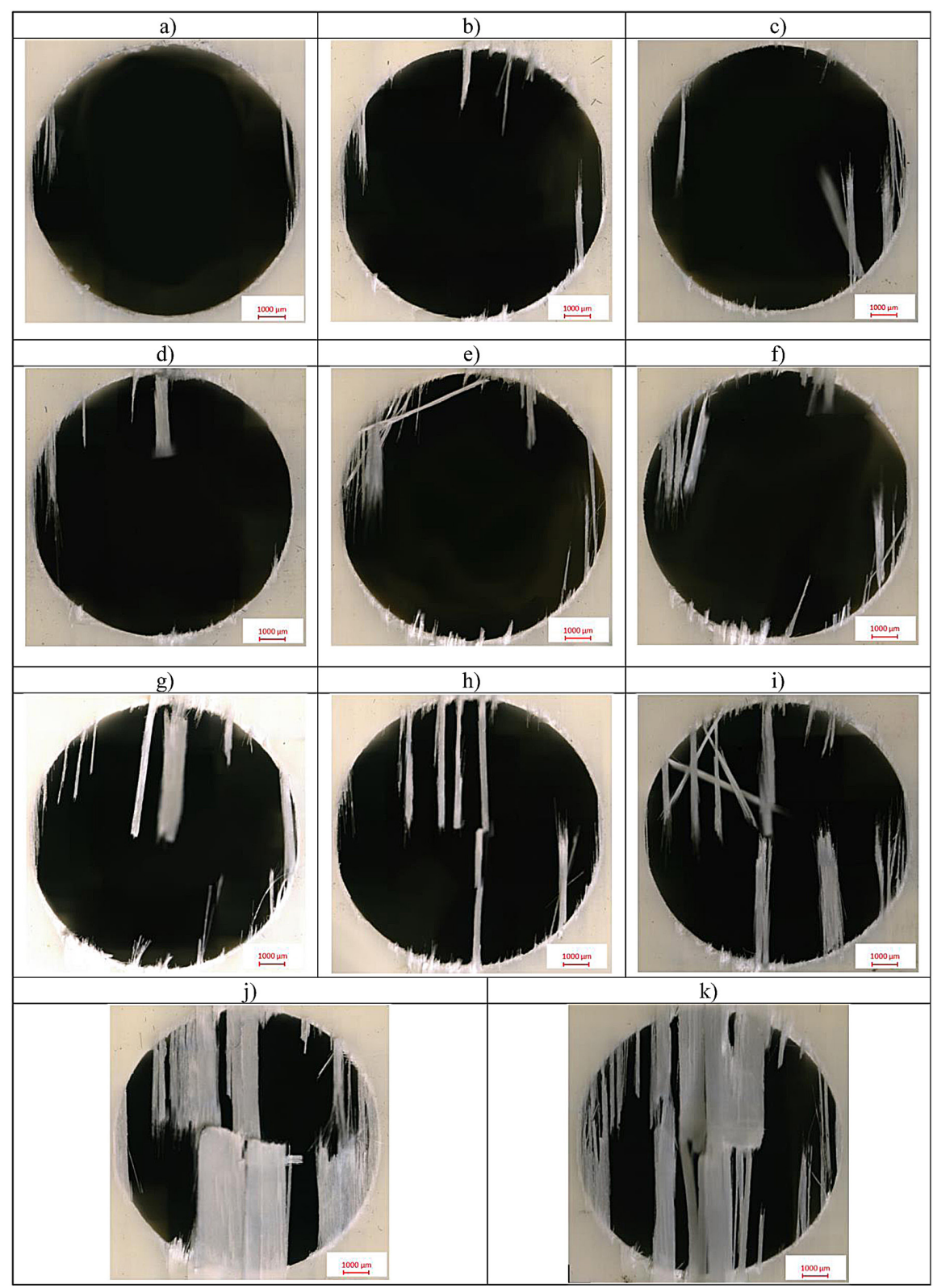

Fig. 6. Photos of the holes drilled in GFRP for the following unsupported element lengths: $16 \mathrm{~mm}$ (a), $28 \mathrm{~mm}$ (b), $40 \mathrm{~mm}$ (c), $52 \mathrm{~mm}$ (d), $64 \mathrm{~mm}$ (e), $76 \mathrm{~mm}$ (f), $88 \mathrm{~mm}$ (g), $100 \mathrm{~mm}$ (h), $112 \mathrm{~mm}$ (i), $124 \mathrm{~mm}$ (j) i $136 \mathrm{~mm}$ (k) 
shows a very similar relationship, but the feed force increases slowly from $550 \mathrm{~N}$ for the shortest unsupported element length to $820 \mathrm{~N}$ for the longest unsupported element length. The feed force increase with increasing the distance from the support point can be explained by elasticity of the workpiece. For the CFRP material the increase in the maximum resistance force with increased length of the element is more dynamic than that observed for the GFRP material. This phenomenon can be explained by greater resistance of the material. The greater resistance is due to the fact that the drill has to break the bonds between the material-reinforcing fibers.
One can also observe an increase in the maximum feed force depending on the length of the element in the exit zone of the tool from the workpiece. This phenomenon occurs for two types of composite materials, but for CFRP it is characterized by a higher feed force. At $l=136 \mathrm{~mm}$ for GFRP this value is $340 \mathrm{~N}$, while for CFRP and the same unsupported element length it is $850 \mathrm{~N}$. For the case of CFRP, there is a visible increase in the maximum feed force in the last zone when the unsupported element length exceeds $l=64 \mathrm{~mm}$. Then there is also a situation in which the feed force in the third zone is greater than the force in the main zone. For the GFRP composite, this relationship

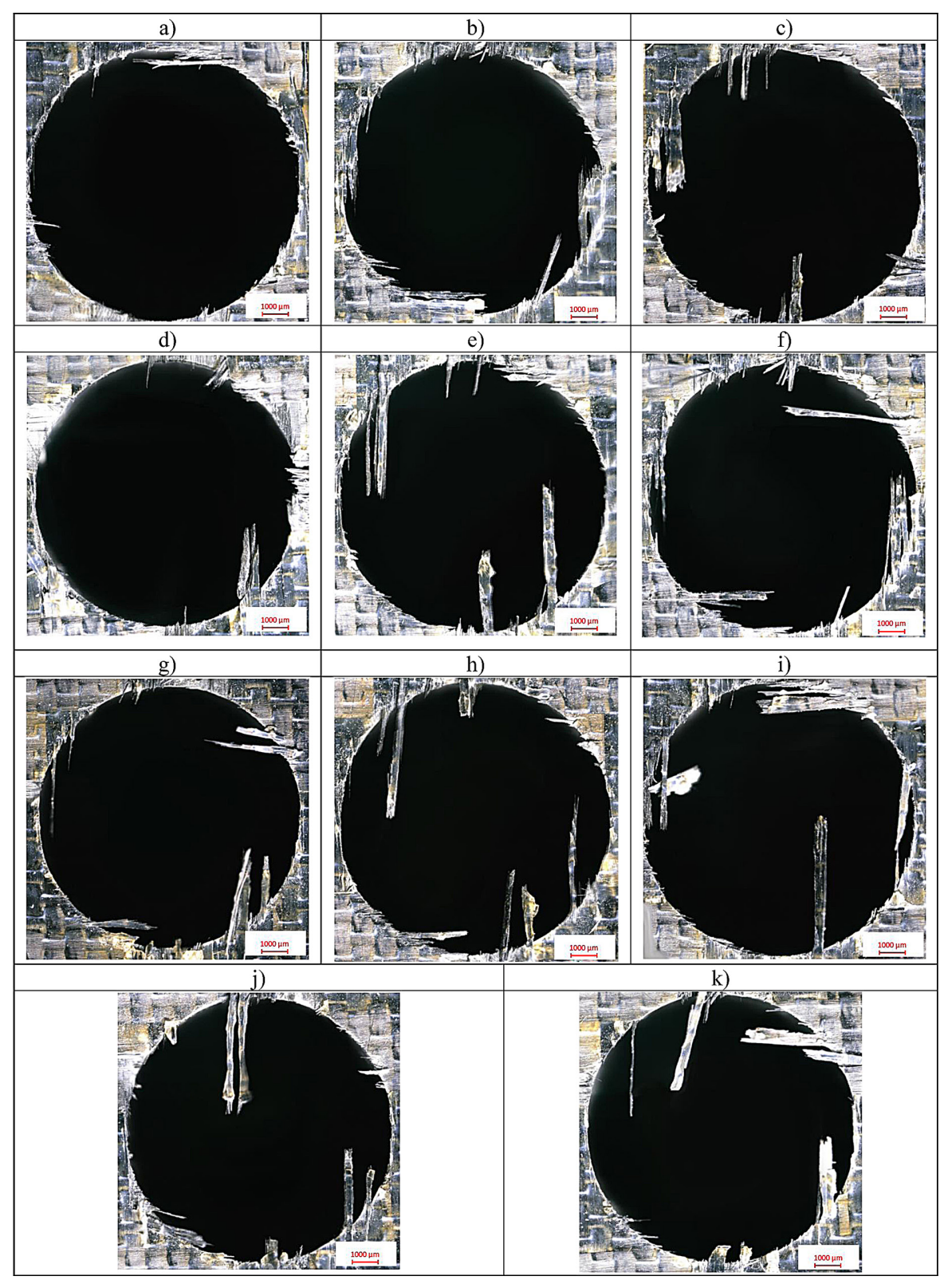

Fig. 7. Photos of the holes drilled in CFRP for the following unsupported element lengths: $16 \mathrm{~mm}$ (a), $28 \mathrm{~mm}$ (b), $40 \mathrm{~mm}$ (c), $52 \mathrm{~mm}$ (d), $64 \mathrm{~mm}$ (e), $76 \mathrm{~mm}$ (f), $88 \mathrm{~mm}$ (g), $100 \mathrm{~mm}$ (h), $112 \mathrm{~mm}(\mathrm{i}), 124 \mathrm{~mm}$ (j) i $136 \mathrm{~mm}(\mathrm{k})$ 
also occurs for the unsupported element length $l=$ $64 \mathrm{~mm}$, but the differences between the values of $F_{f}$ from both zones are not as significant as those for the CFRP composite. Above the length $l=64 \mathrm{~mm}$, the cutting resistance is significantly higher, which leads to the maximum feed force.

Figures $6 \mathrm{a}-\mathrm{f}$ and $7 \mathrm{a}-\mathrm{f}$ show the holes made in glass fiber reinforced plastic (Fig. 6) and carbon fibers reinforced plastic (Fig. 7), respectively.

Based on the results of length of the torn fibers remaining in the tool exit zone from the material, a graph shown in Figure 8 was plotted. The graph shows the effect of the length of the element on the average length of the fibers for the two tested composite materials. The blue line marks the results obtained for GFRP, and the red line marks the lengths of detached fibers in CFRP. Standard deviations for both materials were calculated.

In the plot (Fig. 8), one can observe the formation of damage in the composite material with increasing the unsupported element length $l$. A comparison of the two types of materials reveals that GFRP is more susceptible to increase in the length of torn fibers with increasing the unsupported element length. With the unsupported element length set to $l=16 \mathrm{~mm}$, the average length of torn fibers is $1885 \mu \mathrm{m}$, and for the unsupported element length $l=136 \mathrm{~mm}$, this average length value is already $5358 \mu \mathrm{m}$. A clearly noticeable increase in the length of torn fibers occurs for the unsupported element length value exceeding $l=$ $100 \mathrm{~mm}$. In comparison, in the CFRP composite the length of torn fibers is $2340 \mu \mathrm{m}$ for the unsupported element length $l=16 \mathrm{~mm}$ and $3238 \mu \mathrm{m}$ for the unsupported element length $l=136 \mathrm{~mm}$. In this material, the torn fiber lengths increase with unsupported element length to $l=16-40 \mathrm{~mm}$ and for the largest lengths range $l=100-136 \mathrm{~mm}$. The greater delamination in the GFRP composite is related to a lower stiffness of this material.

The elastic action of the workpiece also affects the accuracy of drilled holes. All dimensions of the holes without manufacturing accuracy must be included in the standard of limit deviations for non-tolerated dimensions (ISO 2768).

Figures $9 \mathrm{a}-\mathrm{d}$ and $10 \mathrm{a}-\mathrm{d}$ show the holes made at the following unsupported lengths: $l=100,112,124$ and $136 \mathrm{~mm}$, for both composites under analysis.

An analysis of the hole diameters obtained for GFRP and CFRP reveals that the holes made for a length of $l=136 \mathrm{~mm}$ do not meet the average accuracy class " $\mathrm{m}$ ". The dimensions are greater than the dimension tolerance for a $100 \mathrm{~mm}$ diameter by $\pm 0.02 \mathrm{~mm}$. For the GFRP composite, the holes made with the unsupported element lengths of $112 \mathrm{~mm}$ and $124 \mathrm{~mm}$ do not meet the good accuracy class "f", and for the CFRP composite the holes made with the unsupported element length of $124 \mathrm{~mm}$ are on the border of the accuracy class " $f$ ". For the GFRP composite, the holes made with the unsupported element length of 100 $\mathrm{mm}$ meet the highest accuracy class. For the case of the CFRP composite, the holes made with the unsupported element length of $112 \mathrm{~mm}$ meet the accuracy class " $\mathrm{f}$ " because the dimensions are within the specified accuracy of $\pm 0.01 \mathrm{~mm}$.

\section{CONCLUSIONS}

This paper presented the results of a study investigating the drilling process for GFRP and CFRP composites. The effects of the unsupported composite material element length on the feed force, delamination and hole accuracy were analyzed. To determine the maximum feed force value, three

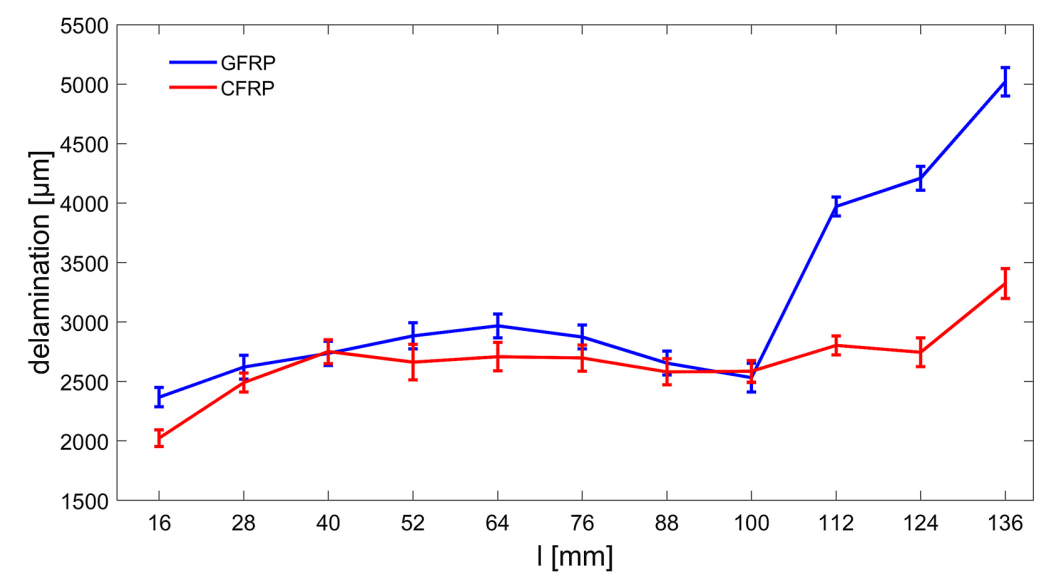

Fig. 8. Graph illustrating the influence of unsupported element length on the average length of torn fibers 


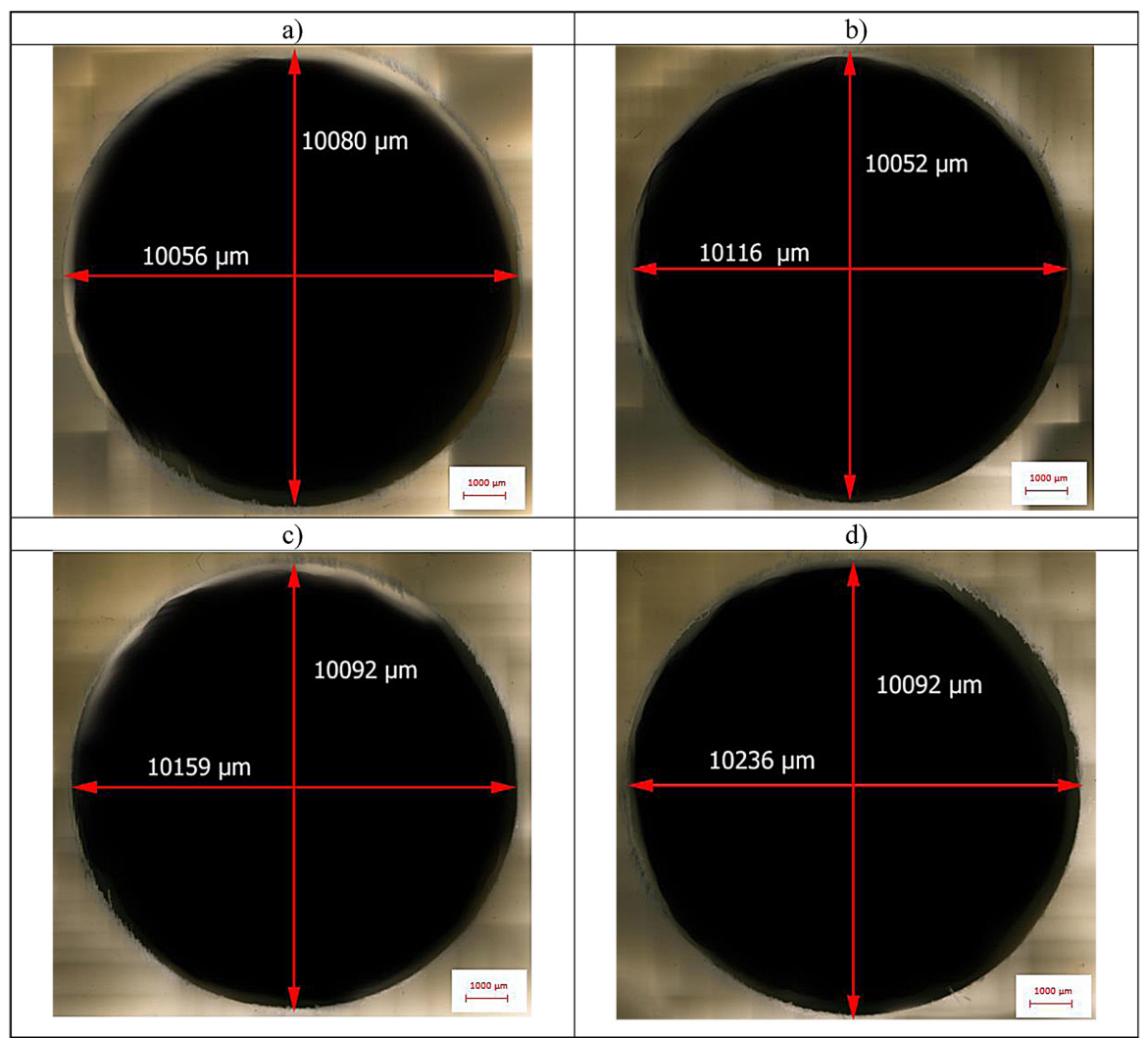

Fig. 9. Measurements of the holes drilled in GFRP for the unsupported element lengths of: $100 \mathrm{~mm}$ (a), $112 \mathrm{~mm}$ (b), 124 (c) and $136 \mathrm{~mm}$ (d)

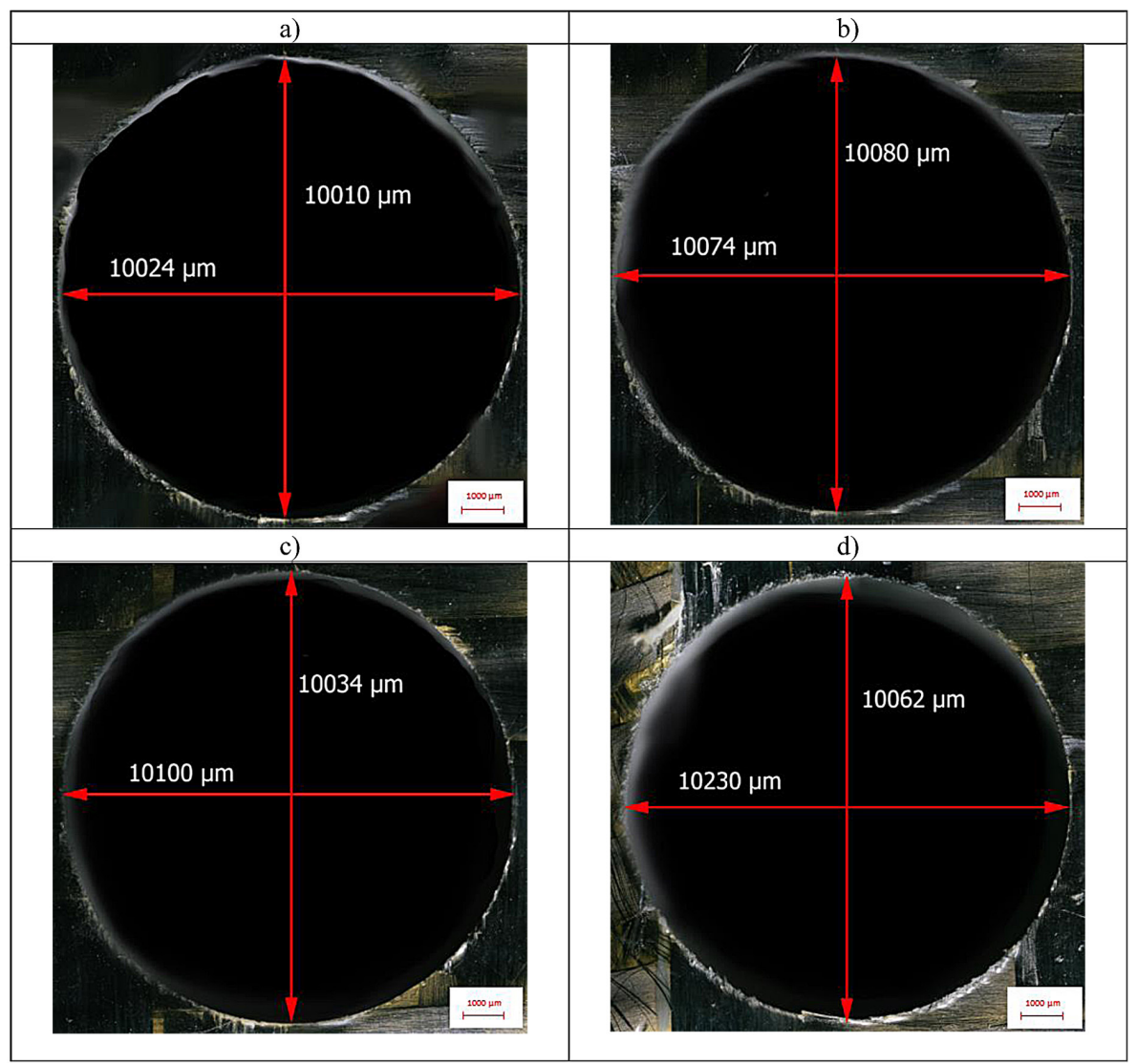

Fig. 10. Measurements of the holes drilled in CFRP for the unsupported element lengths of: $100 \mathrm{~mm}$ (a), $112 \mathrm{~mm}$ (b), 124 (c) and $136 \mathrm{~mm}$ (d) 
drilling zones were identified. Based on the results, the following conclusions can be drawn:

1. Measurements of the feed force have shown that for both composite materials, both in the main zone and in the zone of tool exit from the workpiece, the feed force increases with increasing the length of the element. Based on the recorded waveforms of the feed force, one can observe a visible increase in the feed force toward the final stage of the drilling operation, i.e., when the tool leaves the workpiece.

2. It has been shown that the increase in unsupported element length also affects the length of torn fibers. Due to a lower stiffness of the GFRP material and weaker bonds between the glass fibers, the number of broken fibers was considerably higher and rapidly increased for the unsupported element length exceeding $100 \mathrm{~mm}$. In the CFRP composite, there also occurred an increase in delamination with increasing the unsupported element length, but it was not as dynamic as that observed for GFRP.

3. The elastic deflection of the material also affects the accuracy of the drilled hole. It has been found that for both materials with the greatest tested unsupported element length $(l=136 \mathrm{~mm})$, the holes did not meet even the average accuracy class of non-tolerated linear dimensions. It is thus recommended that holes be drilled with the unsupported element length not exceeding 100 $\mathrm{mm}$ for GFRP and $112 \mathrm{~mm}$ for CFRP.

We concluded that insufficient support of the workpiece has a negative effect on the feed force, delamination and hole accuracy. The next step of the research is comparison of the results of this work with the stiffness of the element and measure vibration produced when drilling holes in polymer composites.

\section{Acknowledgement}

The project/research was financed in the framework of the project Lublin University of Technology - Regional Excellence Initiative, funded by the Polish Ministry of Science and Higher Education (contract no. 030/RID/2018/19).

\section{REFERENCES}

1. Teti R. (2002) Machining of Composite Materials. CIRP Annals 51:611-634.

2. Sathishkumar T., Satheeshkumar S., Naveen J. (2014) Glass fiber-reinforced polymer composites
- a review. Journal of Reinforced Plastics and Composites 33:1258-1275.

3. Gay D., Hoa S.V. (2014) Composite materials: design and applications, 3. ed. CRC Press, Boca Raton, Fla.

4. Caggiano A. (2018) Machining of Fibre Reinforced Plastic Composite Materials. Materials 11:442.

5. Abrão A.M., Faria P.E., Rubio J.C.C., Reis P., Davim J.P. (2007) Drilling of fiber reinforced plastics: A review. Journal of Materials Processing Technology $186: 1-7$.

6. Voisey K.T., Fouquet S., Roy D., Clyne T.W. (2006) Fibre swelling during laser drilling of carbon fibre composites. Optics and Lasers in Engineering 44:1185-1197.

7. Herzog D., Jaeschke P., Meier O., Haferkamp H. (2008) Investigations on the thermal effect caused by laser cutting with respect to static strength of CFRP. International Journal of Machine Tools and Manufacture 48:1464-1473.

8. Lemma E., Chen L., Siores E., Wang J. (2002) Study of cutting fiber-reinforced composites by using abrasive water-jet with cutting head oscillation. Composite Structures 57:297-303.

9. Lau W.S., Wang M., Lee W.B. (1990) Electrical discharge machining of carbon fibre composite materials. International Journal of Machine Tools and Manufacture 30:297-308.

10. Chang C.S. (2006) Turning of glass-fiber reinforced plastics materials with chamfered main cutting edge carbide tools. Journal of Materials Processing Technology 180:117-129.

11. Kini M.V., Chincholkar A.M. (2010) Effect of machining parameters on surface roughness and material removal rate in finish turning of $\pm 30^{\circ}$ glass fibre reinforced polymer pipes. Materials \& Design 31:3590-3598.

12. Bayraktar S., Turgut Y. (2016) Investigation of the cutting forces and surface roughness in milling carbon-fiber-reinforced polymer composite material. Mater Tehnol 50:591-600.

13. Sorrentino L., Turchetta S. (2014) Cutting Forces in Milling of Carbon Fibre Reinforced Plastics. International Journal of Manufacturing Engineering 2014:1-8.

14. He Y., Qing H., Zhang S., Wang D., Zhu S. (2017) The cutting force and defect analysis in milling of carbon fiber-reinforced polymer (CFRP) composite. Int J Adv Manuf Technol 93:1829-1842

15. Azmi A.I., Lin R.J.T., Bhattacharyya D. (2013) Machinability study of glass fibre-reinforced polymer composites during end milling. Int J Adv Manuf Technol 64:247-261.

16. Liu D., Tang Y., Cong W.L. (2012) A review of mechanical drilling for composite laminates. Composite Structures 94:1265-1279. 
17. Stone R., Krishnamurthy K. (1996) A neural network thrust force controller to minimize delamination during drilling of graphite-epoxy laminates. International Journal of Machine Tools and Manufacture 36:985-1003.

18. Park K.Y., Choi J.H., Lee D.G. (1995) Delamination-Free and High Efficiency Drilling of Carbon Fiber Reinforced Plastics. Journal of Composite Materials 29:1988-2002.

19. Rahme P., Landon Y., Lachaud F., Piquet R., Lagarrigue P. (2015) Delamination-free drilling of thick composite materials. Composites Part A: Applied Science and Manufacturing 72:148-159.

20. Hocheng H., Tsao C.C. (2005) The path towards delamination-free drilling of composite materials. Journal of Materials Processing Technology 167:251-264.

21. Linbo Z., Lijiang W., Xin W. (2003) Study on vibration drilling of fiber reinforced plastics with hybrid variation parameters method. Composites Part A: Applied Science and Manufacturing 34:237-244.

22. Lin S.C., Chen I.K. (1996) Drilling carbon fiberreinforced composite material at high speed. Wear 194:156-162.

23. Brinksmeier E., Fangmann S., Rentsch R. (2011) Drilling of composites and resulting surface integrity. CIRP Annals 60:57-60.

24. Lee S.C., Jeong S.T., Park J.N., Kim S.J., Cho G.J. (2008) Study on Drilling Characteristics and Mechanical Properties of CFRP Composites. Acta Mech Solida Sin 21:364-368.

25. Eneyew E.D., Ramulu M. (2014) Experimental study of surface quality and damage when drilling unidirectional CFRP composites. Journal of Materials Research and Technology 3:354-362.

26. Murphy C., Byrne G., Gilchrist M.D. (2002) The performance of coated tungsten carbide drills when machining carbon fibre-reinforced epoxy composite materials. Proceedings of the Institution of Mechanical Engineers, Part B: Journal of Engineering Manufacture 216:143-152.

27. Chen W.C. (1997) Some experimental investigations in the drilling of carbon fiber-reinforced plastic (CFRP) composite laminates. International Journal of Machine Tools and Manufacture 37:1097-1108.

28. Skoczylas A., Zaleski K. (2019) Effect of Centrifugal Shot Peening on the Surface Properties of Laser-Cut C45 Steel Parts. Materials 12:3635.

29. Skoczylas A., Zaleski K. (2020) Selected Properties of the Surface Layer of C45 Steel Parts Subjected to Laser Cutting and Ball Burnishing. Materials 13:3429.

30. Bartoszuk M. (2020) Temperature and Heat Partition Testing in the Cutting Zone for Turning AISI 321 Steel. SV-JME 66:629-641.
31. Klonica M., Matuszak J., Zagorski I. (2019) Effect of Milling Technology on Selected Surface Layer Properties. In: 2019 IEEE 5th International Workshop on Metrology for AeroSpace (MetroAeroSpace). IEEE, Torino, Italy, pp 371-375.

32. Matuszak J., Klonica M., Zagorski I. (2019) Effect of Brushing Conditions on Axial Forces in Ceramic Brush Surface Treatment. In: 2019 IEEE 5th International Workshop on Metrology for AeroSpace (MetroAeroSpace). IEEE, Torino, Italy, pp 644-648.

33. Kecik K., Ciecielag K., Zaleski K. (2017) Damage detection of composite milling process by recurrence plots and quantifications analysis. Int $\mathrm{J} \mathrm{Adv}$ Manuf Technol 89:133-144.

34. Ciecieląg K., Kecik K., Zaleski K. (2020) Defects detection from time series of cutting force in composite milling process by recurrence analysis. Journal of Reinforced Plastics and Composites 39:890-901.

35. Kecik K., Ciecielag K., Zaleski K. (2020) Damage detection by recurrence and entropy methods on the basis of time series measured during composite milling. Int J Adv Manuf Technol 111:549-563.

36. Ciecieląg K., Kęcik K., Zaleski K. (2020) Effect of Depth Surface Defects in Carbon Fibre Reinforced Composite Material on the Selected Recurrence Quantifications. Advances in Materials Science 20:71-80.

37. Geier N., Davim J.P., Szalay T. (2019) Advanced cutting tools and technologies for drilling carbon fibre reinforced polymer (CFRP) composites: A review. Composites Part A: Applied Science and Manufacturing 125:105552.

38. Langella A., Nele L., Maio A. (2005) A torque and thrust prediction model for drilling of composite materials. Composites Part A: Applied Science and Manufacturing 36:83-93.

39. Fernandes M., Cook C. (2006) Drilling of carbon composites using a one shot drill bit. Part I: Five stage representation of drilling and factors affecting maximum force and torque. International Journal of Machine Tools and Manufacture 46:70-75.

40. Fernandes M., Cook C. (2006) Drilling of carbon composites using a one shot drill bit. Part II: empirical modeling of maximum thrust force. International Journal of Machine Tools and Manufacture 46:76-79.

41. Tsao C.C., Hocheng H. (2007) Parametric study on thrust force of core drill. Journal of Materials Processing Technology 192-193:37-40.

42. Wang X., Wang L.J., Tao J.P. (2004) Investigation on thrust in vibration drilling of fiber-reinforced plastics. Journal of Materials Processing Technology 148:239-244. 
43. Ramkumar J., Malhotra S.K., Krishnamurthy R. (2004) Effect of workpiece vibration on drilling of GFRP laminates. Journal of Materials Processing Technology 152:329-332.

44. Krishnamurthy R., Ramkumar J., Aravindan S., Malhotra S.K. (2004) An enhancement of the machining performance of GFRP by oscillatory assisted drilling. The International Journal of Advanced Manufacturing Technology 23:240-244.

45. Krishnaraj V., Prabukarthi A., Ramanathan. A, Elanghovan. N, Senthil Kumar M., Zitoune R., Davim J.P. (2012) Optimization of machining parameters at high speed drilling of carbon fiber reinforced plastic (CFRP) laminates. Composites Part B: Engineering 43:1791-1799.
46. Campos Rubio J., Abrao A.M., Faria P.E., Correia A.E., Davim J.P. (2008) Effects of high speed in the drilling of glass fibre reinforced plastic: Evaluation of the delamination factor. International Journal of Machine Tools and Manufacture 48:715-720.

47. Raja R., Sabitha Jannet R.R. Sabitha Jannet, TJPRC (2017) Experimental Investigation of High Speed Drilling of Glass Fiber Reinforced Plastic (GFRP) Composite Laminates Made up of Different Polymer Matrices. IJMPERD 7:351-358.

48. Campos Rubio J.C., Abrão A.M., Eustáquio Faria P., Correia A.E., Davim J.P. (2008) Delamination in High Speed Drilling of Carbon Fiber Reinforced Plastic (CFRP). Journal of Composite Materials 42:1523-1532. 